\title{
Relationship between CCL22 Expression by Vascular Smooth Muscle Cells and Macrophage Histamine Receptors in Atherosclerosis
}

\author{
Satoshi Kimura ${ }^{1}$, Hirotsugu Noguchi ${ }^{1}$, Uki Nanbu ${ }^{1}$, Ke-Yong Wang ${ }^{2}$, Yasuyuki Sasaguri ${ }^{1}$ and \\ Toshiyuki Nakayama ${ }^{1}$ \\ ${ }^{1}$ Department of Pathology, School of Medicine, University of Occupational and Environmental Health, Kitakyushu, Japan \\ ${ }^{2}$ Shared-Use Research Center, University of Occupational and Environmental Health, Kitakyushu, Japan
}

Aim: CCL22, mainly synthesized by monocyte-derived alternative (M2) macrophages, belongs to the CC family of chemokines and is involved in monocyte migration and recruitment. We have previously investigated CCL22 and histamine in atherosclerosis. Here, we investigated the hypothesis that CCL22 is involved in atherosclerosis, which is influenced by the differentiation of macrophage phenotypes via histamine.

Methods: CCL22 expression was investigated in human carotid arteries and coronary arteries with bare metal stents. Ligated carotid arteries of wild-type $(\mathrm{C} 57 \mathrm{BL} / 6 \mathrm{~J})$ and apolipoprotein E-deficient mice were also used as atherosclerotic models. The localization and expression of CCL22 and classical (M1)-like and M2-like macrophages in various human and mouse atherosclerotic lesions were investigated by immunohistochemical examination and quantitative real-time polymerase chain reaction. Histamine is expressed in atherosclerosis, and it induces inflammation and immunity. Human- and mice-derived monocytes and macrophages were used to examine the role of histamine in macrophage differentiation and CCL22-expression. Macrophages derived from histamine receptor $1(\mathrm{H} 1 \mathrm{R})$ - and $2(\mathrm{H} 2 \mathrm{R})$-knockout $(\mathrm{KO})$ mice were also examined.

Results: Atherosclerotic lesions showed a distribution of heterogeneous macrophage phenotypes with M1-like and M2-like macrophage dominant sites. CCL22 was distributed in sparse areas of vascular smooth muscle cells (VSMCs) and associated with M2-like macrophages. Moreover, H2R stimulation was associated with CCL22 expression via M2-like macrophage dominant differentiation.

Conclusion: The expression of M1- or M2-like macrophages in atherosclerosis were observed to be dependent on the distribution of VSMCs owing to differences in causal stimuli and the switching of histamine receptors via Th1 or Th2 cytokines. These results suggest that CCL22 may control atherosclerosis.

Key words: CCL22, Histamine, Atherosclerosis, Macrophage, Chemokine

\section{Introduction}

Of the various cytokines involved in inflammation, chemotactic peptides known as chemokines that are induced in response to inflammatory and immunological stimuli are the most significant in terms of leukocyte recruitment. More than 50 known humanchemokines are grouped into four families on the basis of conserved cysteine residues near their amino termini and are designated as $\mathrm{C}, \mathrm{CC}, \mathrm{CXC}$, and $\mathrm{CX} 3 \mathrm{C}$ subfamilies. CCL22 is a member of the CC subfam- ily $^{1,2)}$.

Atherosclerosis is a progressive, inflammatory disease of the arterial wall modulated by immune responses. The initial step in atherosclerosis involves the infiltration of monocytes into the arterial wall ${ }^{3)}$. After monocytes have adhered to the endothelium, they migrate into the intima, where they can differentiate into macrophages and phagocytose lipids to become foam cells $s^{4,5)}$. Macrophages are a predominant source of cytokines, growth factors, and chemokines, including CCL22 that contribute to the recruitment of monocytes in the sub-

Address for correspondence: Satoshi Kimura, Department of Pathology, School of Medicine, University of Occupational and Environmental Health, 1-1 Iseigaoka, Yahatanishi-ku, Kitakyushu, 807-8555 Japan E-mail: s-kimura@med.uoeh-u.ac.jp

Received: January 25, 2018 Accepted for publication: March 28, 2018

Copyright@2018 Japan Atherosclerosis Society

This article is distributed under the terms of the latest version of CC BY-NC-SA defined by the Creative Commons Attribution License. 
endothelial space ${ }^{6}$. In addition to macrophages, dendritic cells are also present in the atherosclerotic lesions and produce more CCL22 than monocytes ${ }^{1,6-9)}$.

Macrophages are present in various regions of plaque, and are exposed to different environmental stimuli that modulate their activation and polarization. Even though the process of differentiation of monocytes into macrophages is irreversible, macrophage-polarization appears reversible ${ }^{10,11)}$. Monocyte-derived macrophages are the principal mediators of tissue homeostasis and repair along with the response to pathogenesis and inflammation in organs ${ }^{12)}$. Macrophages can be divided into classically Th1 polarized M1-like and Th2 polarized M2-like macrophage phenotypes ${ }^{13}$ 14). In addition to M1-like macrophages, M2-like macrophages are present in the atherosclerotic lesions ${ }^{15)}$ and contribute to the pathogenesis of atherosclerosis ${ }^{16)}$. Furthermore, M2-like macrophages express CCL22 ${ }^{17)}$.

Histamine is one of the principal mediators of allergic reactions, inflammation, and cardiovascular hemodynamics. Histamine is a classical and immunological mediator, mainly produced by mast cells and basophils. However, in addition to these cells, monocytes and macrophages also produce histamine that is gradually secreted in atherosclerosis ${ }^{18)}$.

Macrophages express CCL22 in response to histamine stimulation via the $\mathrm{H} 2$ receptor ${ }^{19,}{ }^{20)}$. In this study, we investigated the localization of CCL22 and the various macrophage phenotypes in atherosclerotic lesions, and the relationship between macrophage phenotypes and histamine receptors.

\section{Materials and Methods}

\section{Human Arteries}

To investigate human common carotid arteries and the effect of coronary bare metal stents on human coronary arteries by histological and immunohistochemical examinations, 22 samples each that did not show aortitis syndrome and autoimmune disease were obtained at autopsy.

Resected tissues were fixed in 10\% formalin and embedded in paraffin. The sections $(3 \mu \mathrm{m})$ were stained with hematoxylin and eosin (H\&E) and used for immunohistochemical examinations by the EnVision method (Dako Japan, Kyoto, Japan). Monoclonal anti-human CD68 (clone KP1, 1:100) and $\alpha$ SMA (clone 1A/4, 1:150) antibodies were obtained from Dako Japan, rabbit polyclonal antibodies to CCL22 (1:100) and monocyte chemoattractant protein (MCP)-1 (1:200) were obtained from Abcam (Tokyo, Japan), and monoclonal anti-human CD4 antibody (clone 4B12, undiluted) was obtained from Nichirei (Tokyo, Japan).

This investigation adhered to all the principles prescribed in the Declaration of Helsinki. The Ethics Committee of Experimentation, University of Occupational and Environmental Health, Japan, approved all procedures of the present study.

\section{Animals}

We used male apoE knockout $(\mathrm{KO})$ mice (Jackson Laboratory, Bar Harbor, ME) that were maintained for 30 weeks on a normal chow diet. Another group of male wild-type (WT) C57BL/6J mice (Charles River, Yokohama, Japan), weaned at 8 weeks of age, was used to produce ligation-induced vascular injury models. We ligated the left common carotid artery with a 7-0 silk suture for 2 weeks at a site proximal to the carotid bifurcation.

After the animals were euthanized, carotid arteries were removed, fixed in 10\% formalin, and embedded in paraffin for histological and immunohistochemical examination as described previously ${ }^{21)}$. Thin sections $(3 \mu \mathrm{m})$ were cut and stained with $\mathrm{H} \& \mathrm{E}$ and used for immunohistochemical detection. Immunohistochemical staining was carried out (EnVision kit, Dako Japan) using antibodies against CCL22 (rabbit polyclonal, 1:50; Gene'Tex, Irvine, CA), Mac-3 (clone M3/84, 1:50; BD Bioscience Pharmingen, Tokyo, Japan), and $\alpha$ SMA (1:150; Dako, as above).

\section{Immunofluorescence Staining}

Immunofluorescence assays were performed on thin sections $(4 \mu \mathrm{m})$ of human coronary artery, with and without coronary stenting. Experiments were performed using anti-CCL22 (as described above) and antiCD163 (1:200; Leica Biosystems, Newcastle, UK) primary antibodies to detect M2-like macrophages, and anti-MCP-1 primary antibody (as above) to detect M1like macrophages. In addition, antibodies to $\alpha$ SMA (as above), CD4 (as above), CCR4 (goat polyclonal, 1:100: Abcam), and interleukin (IL)-4 (rabbit polyclonal, 1:2000; Abcam) were used. Rhodamine-conjugated goat anti-mouse $\operatorname{IgG}(\mathrm{H}+\mathrm{L} ; 1: 200)$ and donkey anti-rabbit IgG (1:200; Merck, Tokyo, Japan), and FITC-conjugated goat anti-rabbit IgG $(\mathrm{H}+\mathrm{L})(1: 200)$, donkey anti-mouse $\operatorname{IgG}(\mathrm{H}+\mathrm{L})(1: 200)$ and donkey anti-goat $\operatorname{IgG}(\mathrm{H}+\mathrm{L}$; 1:200; Merck) were used as secondary antibodies, respectively, and incubated for $90 \mathrm{~min}$ at $25^{\circ} \mathrm{C}$. After washing with phosphate buffered saline (PBS), specimens were counterstained with 4', 6-diamidino-2-phenylindole (DAPI; GeneTex, Hsinchu City, Taiwan) and mounted. Immunostained tissues were evaluated with a Nikon ECLIPSE E600 inverted fluorescence microscope (Nikon, Tokyo, Japan). Image analysis was completed with LuminaVision software (version 2.2.2; Mitani Corporation, Tokyo, Japan). 
Table 1. List of Primers and Probes for Real-Time PCR Analysis

\begin{tabular}{llll}
\hline Gene & \multicolumn{1}{c}{ Forward } & \multicolumn{1}{c}{ Reverse } & \multicolumn{1}{c}{ Probe } \\
\hline$H 1 R$ & CTTTAGTGTCTTCATCCTGTGTATTGATC & GTAGCTGAAGCACGGGTCTTG & TGTCCAGCAACCCCTCCGGTACCT \\
$H 2 R$ & CCTTCTCTGCCATTTACCAGTTG & CATCACATCCAGGCTGGTGTAG & AGTGGAGGTTTGGCCAGGTCTTCTGC \\
Il & TTACACATGTTCTCTGGGAAATCG & TTGGTAGCATCCATCATTTCTTTG & TGAGAAAAGAGTTGTGCAATGGCAATTCTGAT \\
$i N O S$ & GCAGTGGAGAGATTTTGCATGAC & ATGGACCCCAAGCAAGACTTG & CACCACAAGGCCACATCGGATTTCAC \\
TNF- $\alpha$ & CCCAGACCCTCACACTCAGATC & TGCTCCTCCACTTGGTGGTT & ATTCGAGTGACAAGCCTGTAGCCCACG \\
\hline
\end{tabular}

\section{Cell Cultures}

The murine macrophage-like cell line, J774A.1, was obtained from the Health Science Research Resources Bank (Tokyo, Japan) and cultured in Dulbecco's minimal essential medium (DMEM) with $10 \%$ fetal bovine serum (FCS). In addition, these cells were treated with $100 \mathrm{ng} / \mathrm{mL}$ of lipopolysaccharide (LPS; Wako, Tokyo, Japan) and $20 \mathrm{ng} / \mathrm{mL}$ of interferon (IFN) $y$ (Wako) for M1-like macrophages or $20 \mathrm{ng} / \mathrm{mL}$ of IL-4 (R\&D Systems, Minneapolis, MN) for M2-like macrophages.

A human macrophage cell line was obtained from PromoCell GmbH (Heidelberg, Germany) and cultured in Monocyte Attachment Medium (PromoCell $\mathrm{GmbH})$. In addition, for their differentiation into M1- and M2-like macrophages, cells were cultured in M1-Macrophage Generation Medium DXF (PromoCell $\mathrm{GmbH}$ ) and M2-Macrophage Generation Medium DXF (PromoCell GmbH), respectively.

\section{Preparation of Peritoneal Macrophages}

Peritoneal macrophages from 8-week-old WT, $\mathrm{H} 1 \mathrm{R}-\mathrm{KO}$, and H2R-KO mice fed a normal chow diet were isolated by peritoneal lavage with ice-cold PBS, 3 days after the intraperitoneal injection of $2.5 \mathrm{~mL}$ of $4.05 \%(\mathrm{wt} / \mathrm{vol})$ sterile thioglycollate medium (Becton Dickinson, Franklin Lakes, NJ) as described in our previous studies ${ }^{20,21)}$.

\section{Real-Time Polymerase Chain Reaction}

Quantitative real-time polymerase chain reaction (qPCR) was carried out using a TaqMan assay and a 7700 Sequence Detection System (Applied Biosystems, Foster City, CA). The conditions for PCR were $95^{\circ} \mathrm{C}$ for $10 \mathrm{~min}$, followed by 40 cycles at $95^{\circ} \mathrm{C}$ for $15 \mathrm{sec}$ (denaturation) and $60^{\circ} \mathrm{C}$ for $1 \mathrm{~min}$ (annealing-extension). The primers and fluorogenic probes for CCL22 and IL-4 were from a pre-made primer/probe set (assay ID, Mm00436439_ml and Mm00445259_ml; Applied Biosystems Japan, Ltd., Tokyo, Japan). Primers for the $\mathrm{H} 1$ and $\mathrm{H} 2$ receptors, inducible nitric oxide synthase (iNOS), interleukin (IL)-6, and tumor necrosis factor (TNF)- $\alpha$ have been listed in Table 1 . The levels of
mRNA expression were normalized with those of the expression of 18 s ribosomal RNA in the same samples.

\section{Statistical Analysis}

Analysis of variance (ANOVA) was used to determine statistically significant differences. Data were expressed as mean \pm standard deviation $(\mathrm{SD})$, and a probability $(P)$ value of less than 0.05 was taken to be significant.

\section{Results}

Expression and Localization of CCL22 in Human Common Carotid Arteries

To investigate the expression of CCL22 and its localization in human common carotid arteries, we performed immunohistochemical staining using antibodies against human CCL22, CD68 (a macrophage marker), and $\alpha$ SMA (a smooth muscle cell marker). Although the intimal thickness of the common carotid artery looked relatively concentric at a glance (Fig.1A), the distribution of $\alpha$ SMA in VSMCs in the intima of common carotid arteries were uneven (Fig.1B). The density of VSMCs, classified into three levels $(\alpha, \beta$, and $\gamma$ ), was examined in more detail. Regions with a moderate density of VSMCs $(\alpha)$ showed foamy, CD68positive macrophages and were also positive for CCL22 (Fig. 1C- $\alpha$ H\&E, CD68, CCL22). At sites with a high density of VSMCs $(\beta)$, CD68-positive macrophages were dispersed but were negative for CCL22 (Fig. 1C- $\beta \alpha$ SMA, CD68, CCL22). Vascular smooth muscle cells were not found in regions of concentrated cholesterol clefts $(y)$, while CCL22-staining was strongly positive, and CD68-staining was weakly positive (Fig. 1C- $\gamma \alpha$ SMA, CD68, CCL22). In summary, the expression of CCL22 in atherosclerosis appeared to inversely correlate with the density of VSMCs, with the absence of VSMCs associated with high CCL22 staining (Supplemental Fig.2A).

Expression and Localization of CCL22 in Human Coronary Arteries with Stents

Next, we investigated how arteries artificially in- 

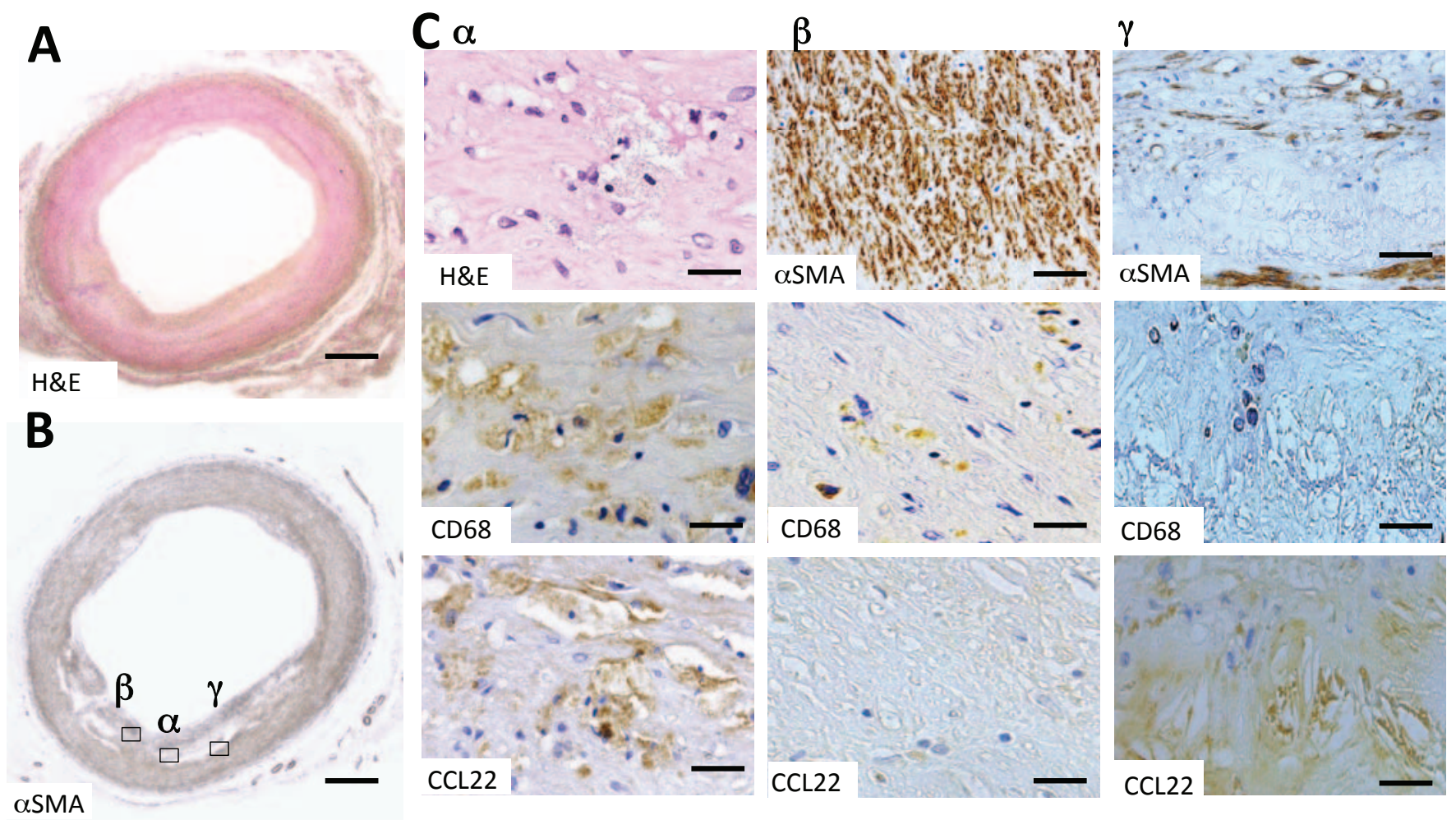

Fig. 1. Expression and localization of CCL22 in a human common carotid artery

Fig. A and Fig. B are low-power magnification images of $\mathrm{H} \& \mathrm{E}(\mathrm{H} \& \mathrm{E})$ and $\alpha$-smooth muscle actin $(\alpha \mathrm{SMA})$ stains. In Fig. B, $\alpha$ signifies an area of intermediate vascular smooth muscle (VSMC) cell density and the accumulation of foamy macrophages, $\beta$ signifies an area with a high degree of VSMC density and $\gamma$ signifies an area with virtually no VSMC. Figures C- $\alpha$ are high-power magnified images showing H \& E and immunohistochemical stains for CD68 and CCL22, respectively, of the $\alpha$-area in Fig. B. Fig. C- $\beta$ shows immunohistochemical staining for $\alpha$ SMA, CD68, and CCL22, respectively, of the $\beta$-area in Fig. B. Fig. C- $\gamma$ shows immunohistochemical staining for $\alpha$ SMA, CD68, and CCL22 of the $\gamma$-area in Fig. B. At first glance, the distribution of VSMCs appeared heterogeneous, even in atherosclerotic lesions that were concentric (A, B).

CD68 positive foamy macrophages were also positive for CCL22 (C- $\alpha$ ). Macrophages in close proximity to VSMC densities were CCL22 negative $(\mathrm{C}-\beta)$. VSMCs were not present around cholesterol clefts; however, positive CCL22 staining was present $(\mathrm{C}-\gamma)$. Bars indicate 1000 $\mu \mathrm{m}(\mathrm{A}$ and $\mathrm{B}), 10 \mu \mathrm{m}(\mathrm{C}-\alpha), 100 \mu \mathrm{m}$ (C- $\beta \alpha \mathrm{SMA}$ and $\mathrm{C}-\gamma \alpha \mathrm{SMA})$, and $50 \mu \mathrm{m}(\mathrm{C}-\beta$ and C- $\gamma$, CD68 and CCL22). The negative control staining of Fig. C- $y$ CCL22 was shown in Supplemental Fig. 1A.

duced the heterogeneous stimulation of VSMCs. Coronary arteries with bare metal stents were used. Staining for $\alpha$ SMA revealed the strong appearance of VSMCs at sites where stent-struts were in direct contact with the arterial wall (Fig.2A, 2B). Macrophages (CD68-positive cells) at sites where VSMCs were dense were CCL22 negative (Fig. 2C H\&E, CD68, $\alpha$ SMA, CCL22). Thus, where VSMCs proliferated, as in the intima, the expression of CCL22 was significantly suppressed as previously found with common carotid arteries (Supplemental Fig. 2B).

\section{Cells Surrounding Macrophages in the Intima}

MCP-1 is known to be one of the cytokines predominantly produced by M1-like macrophages. CCL22negative macrophages were found to express MCP-1 (Fig. 3A MCP-1 and Supplemental Fig.3). Macro- phages were positive for MCP-1 at sites where VSMCs were dense (Fig. 3A $\alpha$ SMA and MCP-1). Several Th2 cells (CD4, CCR4, and IL-4 positive cells) were found surrounding CCL22 positive macrophages (Fig. 3B CD4, CCL22, and CD4, CCR4, IL-4).

Comparison of Expression of CCL22 and CD163 in Atherosclerosis

CD163 is a marker used to assess M2-macrophage distribution; this was compared with the localization of CCL22 using immunofluorescence staining of coronary arteries containing bare metal stents. Where the artery contacted the stent, CD163 and CCL22 were not expressed (Fig.4A, H\&E, CCL22, and CD163). In contrast, the expression of a large amount of both CD163 and CCL22 was observed in intima that did not contact the stent (Fig.4B, H\&E, CCL22, and 

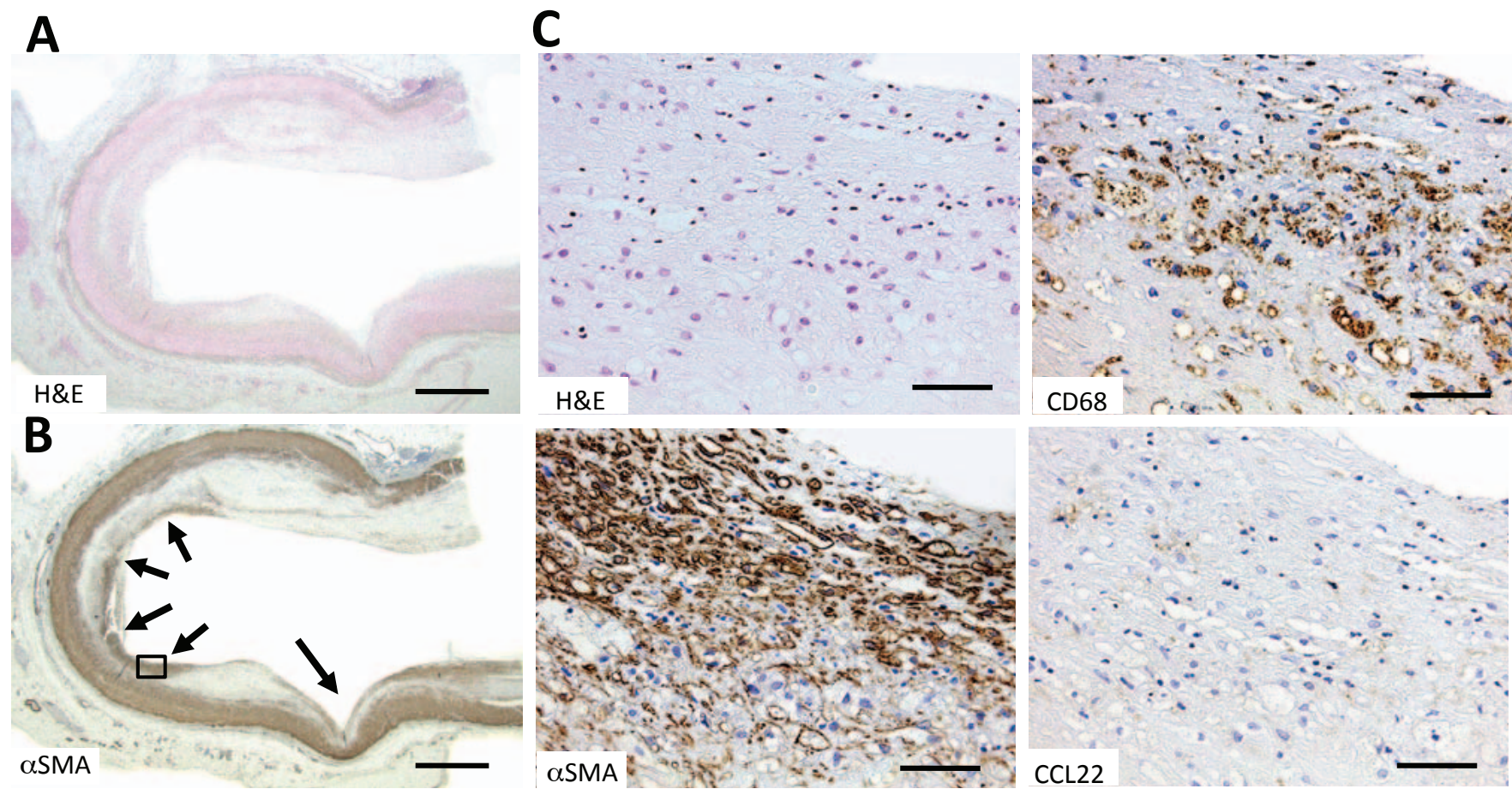

Fig. 2. Histochemical staining of CCL22 in a human coronary artery with a bare metal stent

Fig. A and Fig. B are low-power magnified images of $\mathrm{H} \& \mathrm{E}(\mathrm{H} \& \mathrm{E})$ and $\alpha$-smooth muscle actin $(\alpha \mathrm{SMA})$ stains, respectively. Arrows in Fig. $\mathrm{B}$ indicate the former positions of stent-struts. Fig. C shows high-power magnified images of H \& E, $\alpha$ SMA, CD68, and CCL22 stains, respectively, of the area in the box in Fig. B. Densities of VSMCs were high in the intima of the former contact sites of the stent-struts (Fig. C $\alpha$ SMA) while macrophages at these sites were CCL22-negative (Fig. C CCL22).

Bars indicate $1000 \mu \mathrm{m}$ (Fig. A and B) and $100 \mu \mathrm{m}$ (Fig. C).

CD163). Double staining of CD163 and CCL22 was shown in almost the same cells (Fig.4B, CCL22 [highpower magnification], CD163 [high-power magnification], and CCL22 and CD163). Therefore, in atherosclerosis, CCL22 appears to be expressed in M2-like macrophages.

Expression and Localization of CCL22 in Atherosclerosis in Carotid Arteries of ApoE-KO Mice and Ligation-Induced Neointimal Hyperplasia in Carotid Arteries of Wild-Type Mice

To investigate the difference in localization of VSMCs and CCL22 expression due to differences in the causes of atherosclerosis, we compared common carotid arteries of apoE-KO mice and ligated carotid arteries of WT-mice. We performed immunohistochemical staining using antibodies against mouse CCL22, $\alpha$ SMA, and Mac-3 (a macrophage marker). In the atheroma of an apoE-KO mouse (Fig. 5A), mononuclear cells infiltrating the atheroma were strongly positive for Mac-3 and faintly positive for CCL22; a positive $\alpha$ SMA stain surrounded the atheroma. Lipid clefts in the core of the atheroma were strongly positive for CCL22 (Fig. 5A). Such results are similar to findings relating to atherosclerotic lesions observed in the aortas of humans and apoE-KO mice ${ }^{19,20)}$. M2 macrophages were considered to dominate in this lesion.

In ligation-induced neointimal hyperplasia (Fig. 5B), the intima differed from that of apoE-KO mice. VSMCs were observed to be widely distributed in the thickened intima ( $\alpha \mathrm{SMA})$. Mac-3-positive macrophages were also widely distributed. However, only a few CCL22-positive cells were present. In contrast to the lesions of apoE-KO mice, M1-like macrophages were considered to make up a minor component of the lesion.

\section{Expression of CCL22 and IL-4 mRNAs in Carotid Artery}

qPCR of various mRNAs from the carotid arteries of WT-mice (control), ligated carotid arteries of WT-mice and apoE-KO mice was performed. The relative CCL22-mRNA level was significantly higher in the carotid arteries of apoE- $\mathrm{KO}$ mice than that of the ligated carotid arteries of WT-mice (Fig. 5C; $P<0.01$ ). IL-4 is an important factor for inducing M2-macrophages and showed the same expression pattern as CCL22 (Fig. 5D; $P<0.05$ ). Thus, it appears that the 


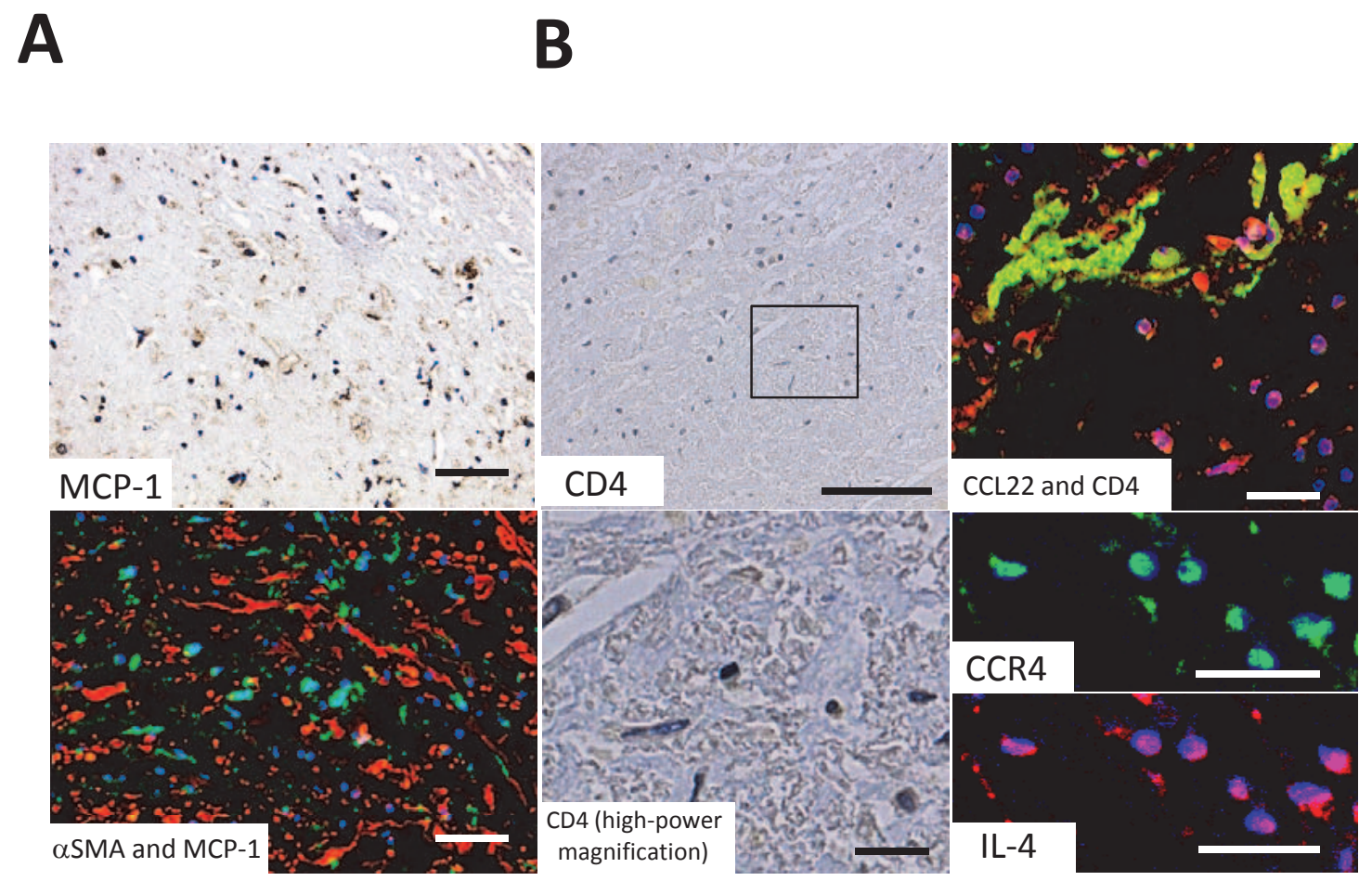

Fig. 3. Cells surrounding macrophages in the intima

Fig. $\mathrm{A}$ is the same area as Fig. $1 \mathrm{~B}-\beta$ and Fig. $\mathrm{B}$ is the same area as 1B- $\gamma$. Fig. A MCP-1 shows monocyte chemoattractant protein (MCP)-1 immunohistochemical staining (green) and Fig. A MCP-1 and $\alpha$-smooth muscle actin $(\alpha$ SMA) shows immunofluorescence staining of both MCP-1 (green) and $\alpha$ SMA (red). MCP-1-positive cells and smooth muscle cells were present in close proximity. Fig. B CD4 and CD4 high-power magnification (high-power magnified image of the box in Fig. B CD4) show the immunohistochemical staining of CD4. Fig. B CCL22 and CD4 show immunofluorescence staining of both CCL22 (green) and CD4 (red). Fig. B CCR4 and interleukin (IL)-4 (highpower magnified image of Fig. B CCL22 and CD4) shows immunofluorescence staining of CCR4 (CCL22 receptor; green) and IL-4 (red). CD4-positive cells appeared around CCL22-positive cells whereas CD4-positive cells showed CCR4-staining and expressed IL-4. Blue staining (DAPI) indicates the nuclei of cells.

Bars indicate $50 \mu \mathrm{m}$ (Fig. A), $100 \mu \mathrm{m}$ (Fig. B CD4) and $30 \mu \mathrm{m}$ (Fig. B CD4 [high-power magnification], CCL22 and CD4, CCR4, and IL-4).

expression of CCL22 in apoE-KO mice correlates with IL-4 expression.

\section{Expression of M1 Macrophage Markers in Carotid Arteries}

IL-6, iNOS, and TNF- $\alpha$ are representative inflammatory cytokines secreted by M1-macrophages. The carotid arteries of WT-mice were used as controls to which the ligated carotid arteries of WT-mice and of apoE-KO mice were compared. Compared with controls, each atherosclerosis model showed an increase in these cytokines. Further, ligated carotid arteries in WTmice showed significantly higher expression of IL-6, iNOS, and TNF- $\alpha$ mRNAs than carotid arteries in apoE-KO mice (Fig. 5E, F, and G; $P<0.01, P<0.05$, and $P<0.01$, respectively).
Role of Histamine Receptors in the Expression of CCL22 and M1-Associated Cytokine mRNAs in Mouse Macrophages

The influence of histamine on the expression of CCL22- and M1-associated IL-6, iNOS, and TNF- $\alpha$ cytokines was examined in macrophages of histamine receptor $\mathrm{KO}$ mice. Previous studies have shown that CCL22 is regulated through the $\mathrm{H} 2$ receptor ${ }^{19)}$. In this study, CCL22-mRNA was significantly decreased in the macrophages of $\mathrm{H} 2$ receptor $\mathrm{KO}(\mathrm{H} 2 \mathrm{R}-\mathrm{KO})$ mice compared to H1R-KO mice (Fig. 6A (i); $P<0.001$ ), despite the serum histamine concentration of H2R-KO mice being significantly higher than that of WT or H1R-KO mice (Supplemental Fig.4; $P<0.05$ for both). In comparison, IL-6, iNOS, and TNF- $\alpha$ mRNAs were significantly decreased in the macrophages of H1R-KO mice compared to $\mathrm{H} 2 \mathrm{R}-\mathrm{KO}$ mice (Fig. 6A (ii), A (iii), and A (iv); $P<0.001, P<0.01$, and $P<0.001$, respectively). Thus, these results sug- 


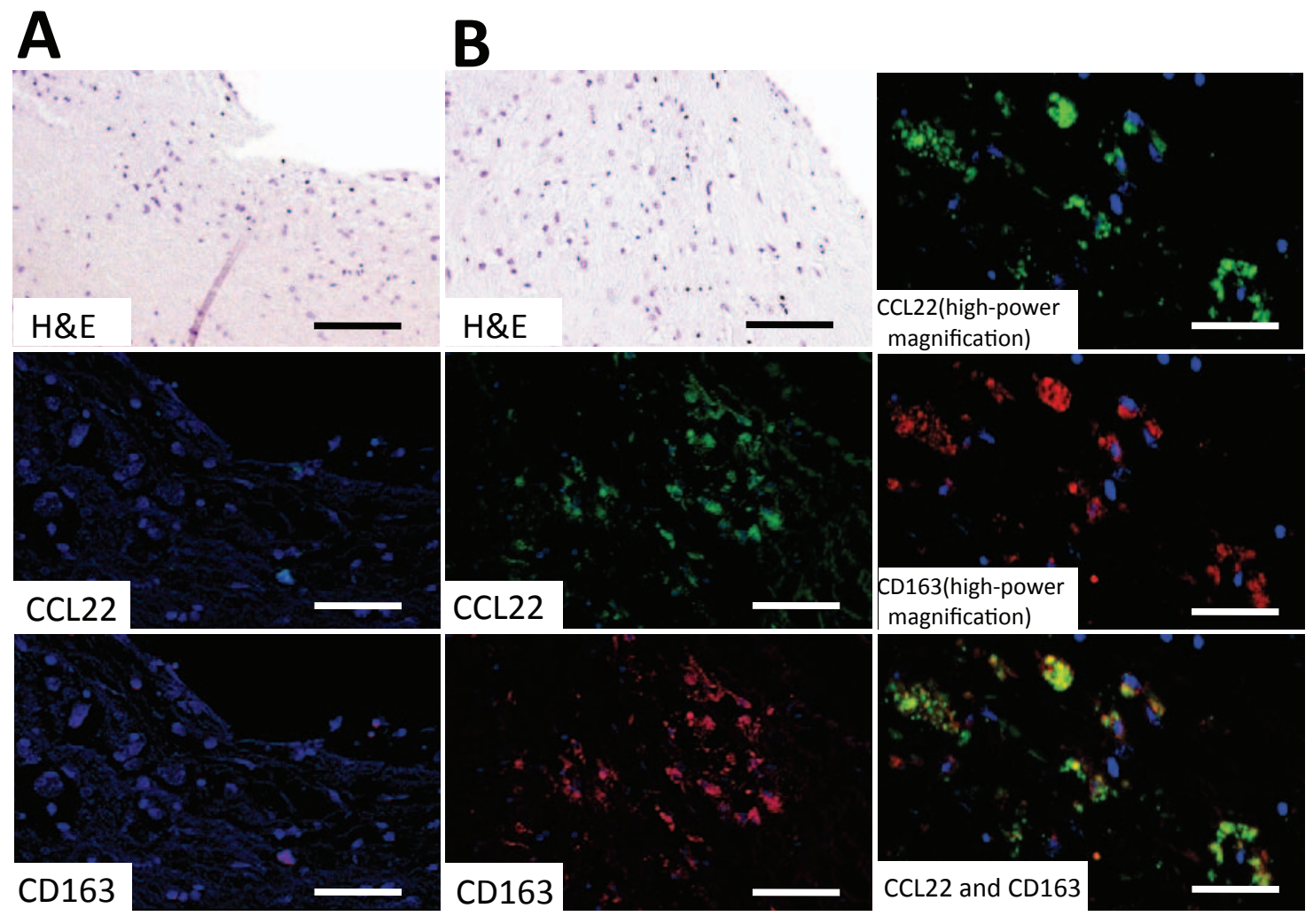

Fig.4. Immunofluorescence staining of CCL22 and CD163 in a human coronary artery with a bare metal stent

Fig. A shows the contact site of the stent-strut and Fig. B shows the lesion between struts. Fig. B CCL22 and CD163 (high-power magnification) are high-power magnified immunofluorescence images of Fig. B H\&E. Fig. A and B CCL22 show immunofluorescence staining for CCL22 (green), and Fig. A and B CD163 show immunofluorescence staining for CD163 (red). Fig. B CCL22 and CD163 images show double immunofluorescence staining of CCL22 and CD163. Almost all of the CCL22-positive cells expressed CD163. Blue staining (DAPI) indicates the nuclei of cells. Bars indicate $200 \mu \mathrm{m}$ (Fig. A, B, H\&E, CCL22, and CD163) and $100 \mu \mathrm{m}$ (Fig. B CCL22, CD163 [high-power magnification], and CCL22, and CD163).

gest that cytokines are regulated through the expression ratio of histamine receptors in macrophages in addition to the switching of histamine receptors in monocyte/macrophages in atherosclerosis ${ }^{18,22)}$.

Expression of Histamine Receptors in Mouse Macrophages and a Human Macrophage Cell Line

The relationship between M1- and M2-like macrophage differentiation, and the expression of histamine receptors was examined in human and mouse monocytes, and in M1- and M2-like macrophages. Human and mouse monocytes were found to express predominantly $\mathrm{H} 2$ compared to $\mathrm{H} 1$ receptors, as found in previous studies (Fig.6B (i) and C (i); $P<0.01$ for both). Human and mouse M1-like macrophages displayed predominantly $\mathrm{H} 1$ compared with $\mathrm{H} 2$ receptors (Fig. 6B (ii) and C (ii); $P<0.01$ and $P<0.05$, respectively). In contrast, for M2-like macrophages, a significant difference in expression of $\mathrm{H} 1$ and $\mathrm{H} 2$ receptors was not found [Fig. 6B (iii) and C (iii)]. Thus, these results suggested that histamine tended to enhance inflammation via M1-like macrophages and tended to increase the expression of CCL22 via M2-like macrophages.

\section{Discussion}

This study is a continuation of our work on the expression of CCL22 in atherosclerotic lesions ${ }^{19,} 20$. We previously found that the expression of CCL22 increased with the maturation of macrophages and the stabilization of lesions, but differences in the cellular localization of CCL22 were not investigated ${ }^{19,20)}$. The migration and proliferation of VSMCs are processes that occur during atherosclerosis ${ }^{23}$, 24), with the nonuniform distribution of VSMCs in the atheroma of the intima one cause for the asymmetric thickenings observed in this tissue. In this study, we examined the 

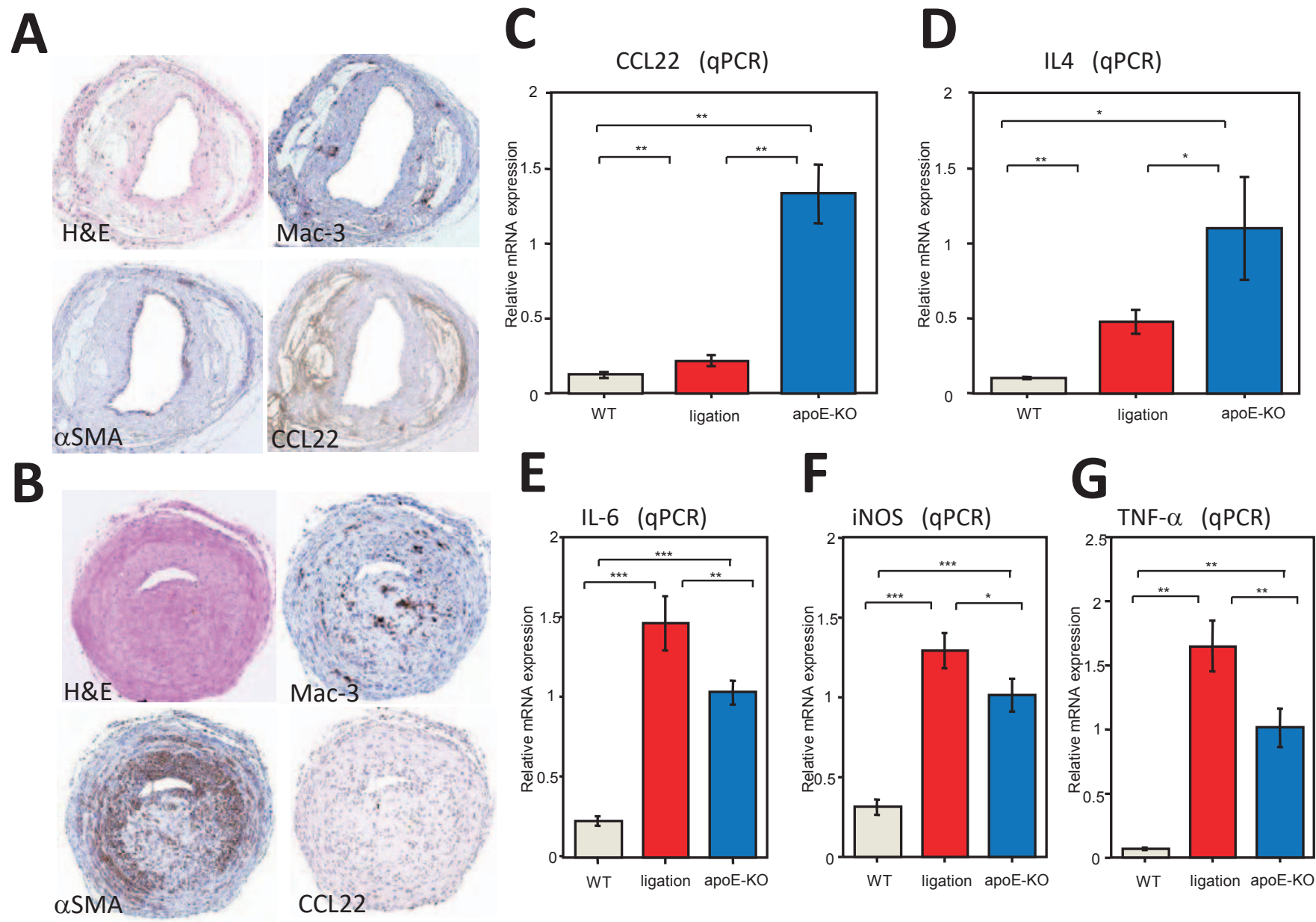

Fig. 5. Expression of CCL22 and cytokine mRNAs in lesions of atherosclerosis mouse models.

Fig. A shows the common carotid artery of an apolipoprotein E (apoE-KO) mouse and Fig. B shows the ligated common carotid artery of a WT mouse. Fig. A and B show H\&E (H \& E), $\alpha$-smooth muscle actin ( $\alpha$ SMA), Mac-3, and CCL22 stains. The atherosclerotic lesion of an apoE-KO mouse showed few VSMCs and expressed a large amount of CCL22 (Fig. A). In contrast, the intima of a ligated common carotid artery of a WT-mouse displayed abundant VSMCs and expressed large amounts of Mac-3, while CCL22 was barely expressed (Fig. B). Realtime (q) PCR of mRNA from common carotid arteries of WT $(n=9)$, ligated WT $(n=9)$, and apoE-KO $(n=9)$ mice was performed $(\mathrm{C}$ and D). Fig. C and D show the expression of CCL22 and interleukin (IL)-4 mRNAs, respectively. The arteries in apoE-KO mice predominantly expressed CCL22 and IL-4 mRNA in comparison with those of WT-mice or ligated arteries of WT-mice. Values represent the mean \pm SD of triplicate measurements from three independent experiments. $\left({ }^{*} P<0.05,{ }^{* *} P<0.01\right)$. qPCR of interleukin (IL)-6 (Fig. E), inducible nitric oxide synthase (iNOS) (Fig. F), and TNF- $\alpha$ (Fig. G) mRNAs from atherosclerotic lesions in common carotid arteries of WT $(n=9)$, ligated WT $(n=9)$, and apoE-KO $(n=9)$ mice were examined. Such cytokines were predominantly expressed in atherosclerotic lesions from ligated common carotid arteries of WT-mice compared with those of apoE-KO mice. Values represent the mean \pm SD of triplicate measurements from three independent experiments. $\left({ }^{*} P<0.05\right.$, ${ }^{* *} P<0.01$, and $\left.{ }^{* * *} P<0.001\right)$. The negative control staining of Fig. A CCL22 was shown in Supplemental Fig. 1B.

relationship between VSMCs and the localization of macrophage subtypes.

M1-like macrophages were mainly present at sites where VSMCs were observed in high density, while M2 -like macrophages were present where VSMCs were sparse. Similar results were observed in coronary arteries in which the distribution of VSMCs was artificially induced by stent placement. VSMCs express IFN $\gamma$, macrophage colony-stimulated factor (M-CSF), and MCP-1 ${ }^{25-27)}$, which allow the migration of macro- phages and their differentiation into M1-like macrophages. Furthermore, contact between monocytes, activated via M-CSF, and VSMCs, as well as the expression of TNF- $\alpha$ leads to apoptosis in VSMCs ${ }^{28,29)}$. The proximity of M1-like macrophages and VSMCs may be one of the factors that create the sparsity of VSMCs observed in areas of atherosclerotic lesions.

We then carried out a comparative study with respect to two different models of atherosclerosis in mice, and with reference to our previous studies ${ }^{20,21,30,31)}$. In 


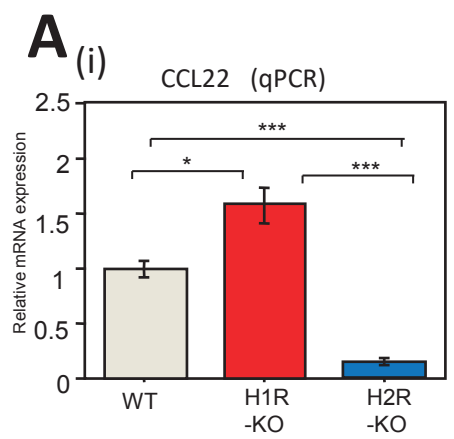

B
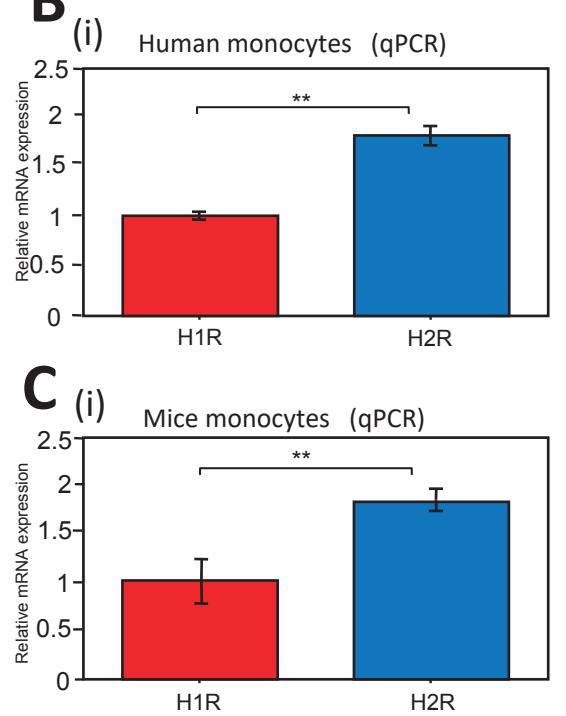

(ii)

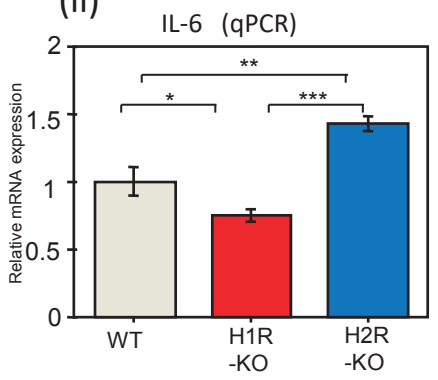

(iii)

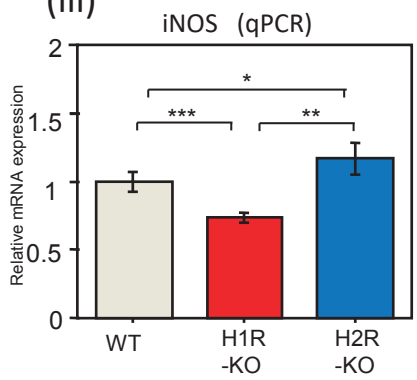

(iv) $\mathrm{TNF}-\alpha$ (qPCR)

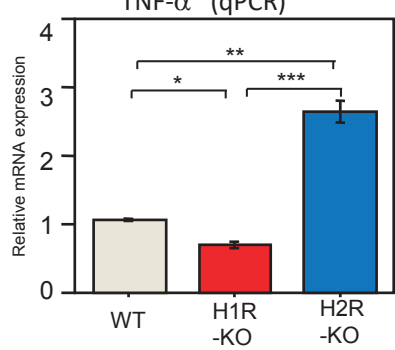

(ii)

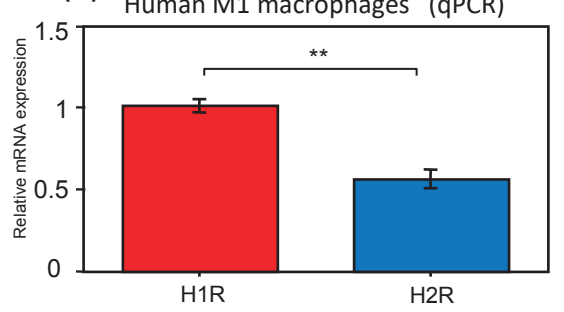

(ii)

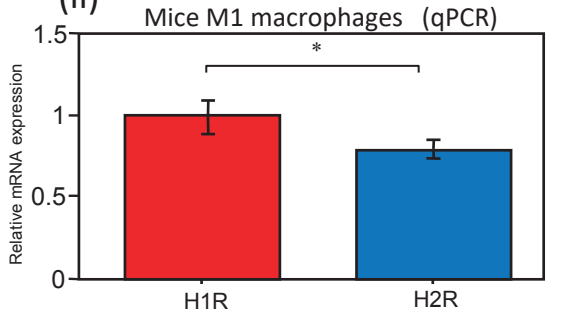

(iii)

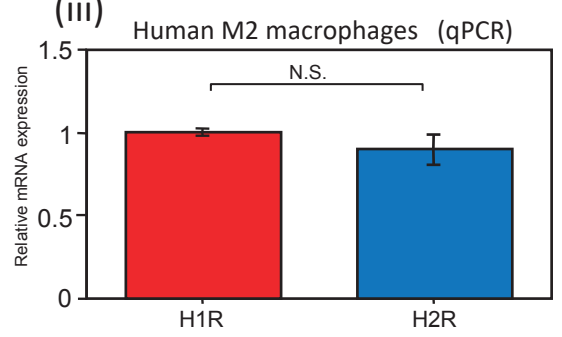

(iii)

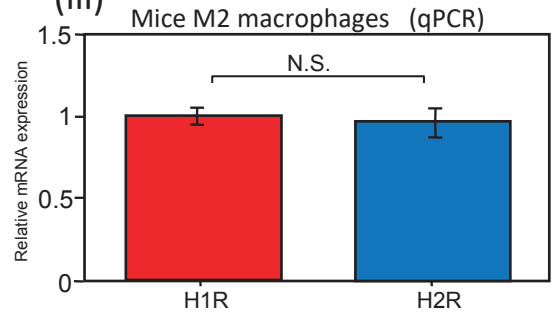

Fig. 6. Regulation of CCL22 and cytokine mRNAs via histamine receptors in macrophages

Fig. A shows real-time (q) PCR of CCL22 (A-i), interleukin (IL)-6 (A-ii), inducible nitric oxide synthase iNOS (A-iii), and TNF- $\alpha$ (A-iv) mRNAs in peritoneal macrophages from WT; $n=10)$, histamine receptor 1 knockout (H1R-KO; $n=10$ ) and histamine receptor 2 knockout (H2R-KO; $n=10$ ) mice. CCL22 was regulated by H2R. In comparison, IL-6, iNOS, and TNF- $\alpha$ were regulated by H1R. Furthermore, we examined the relationship between macrophage phenotypes and histamine receptors. Fig. B and $\mathrm{C}$ relate to human and mouse monocytes and macrophages, respectively. Human (PromoCell) monocytes (B-i) expressed predominantly H2R. In contrast, human M1-like macrophages (B-ii) expressed predominantly H1R. Human M2-like macrophages (B-iii) exhibited intermediate expression of H1R and H2R relative to monocytes and M1-like macrophages, without a significant difference in the expression of H1R and H2R being apparent. Mouse monocytes and macrophages displayed the same trends as for human monocytes and macrophages (C-i, -ii, and -iii). Values represent the mean \pm SD of triplicate measurements from three independent experiments.

$\left({ }^{*} P<0.05,{ }^{* *} P<0.01,{ }^{* * *} P<0.001 ;\right.$ N.S., not significant).

ligation-induced neointimal hyperplasia, intimal hyperplasia was observed mainly in the smooth muscle cell layer. In this model, CCL22-negative macrophages were the dominant macrophages found in atherosclerotic lesions. In the common carotid artery atherosclerosis of apoE-KO mice, lesions were observed with a reduced increase in VSMCs and mainly contained foamy macrophages and cholesterol. In comparing these two experimental models, lesions with mainly smooth muscle cell hyperplasia, similar to human atherosclerosis, showed little expression of CCL22, particularly, in many cases, at sites with few VSMCs.

The expression of CCL22 is generally one of the features of M2 macrophages. We found that the local- ization of M2 macrophages in atherosclerosis is inversely proportional to the distribution of VSMCs. Conversely, it was thought that M1 macrophages migrated to a site with many VSMCs, and that the latter cells then increased at that site. VSMCs express IFN $\gamma^{26)}$, which is thought to promote the differentiation of M1-macrophages and to further increase VSMCs. CCR 4 is a receptor that is expressed mainly in Th2 cells that produce IL- ${ }^{32)}$. In this study, the expression of IL- 4 in the atherosclerotic lesion was observed more abundantly in the carotid arteries of apoE-KO mice than in the ligated carotid arteries of WT-mice.

The regulation of expression of CCL22 has been shown to be related to the $\mathrm{H} 2$ receptor using H1R/ 


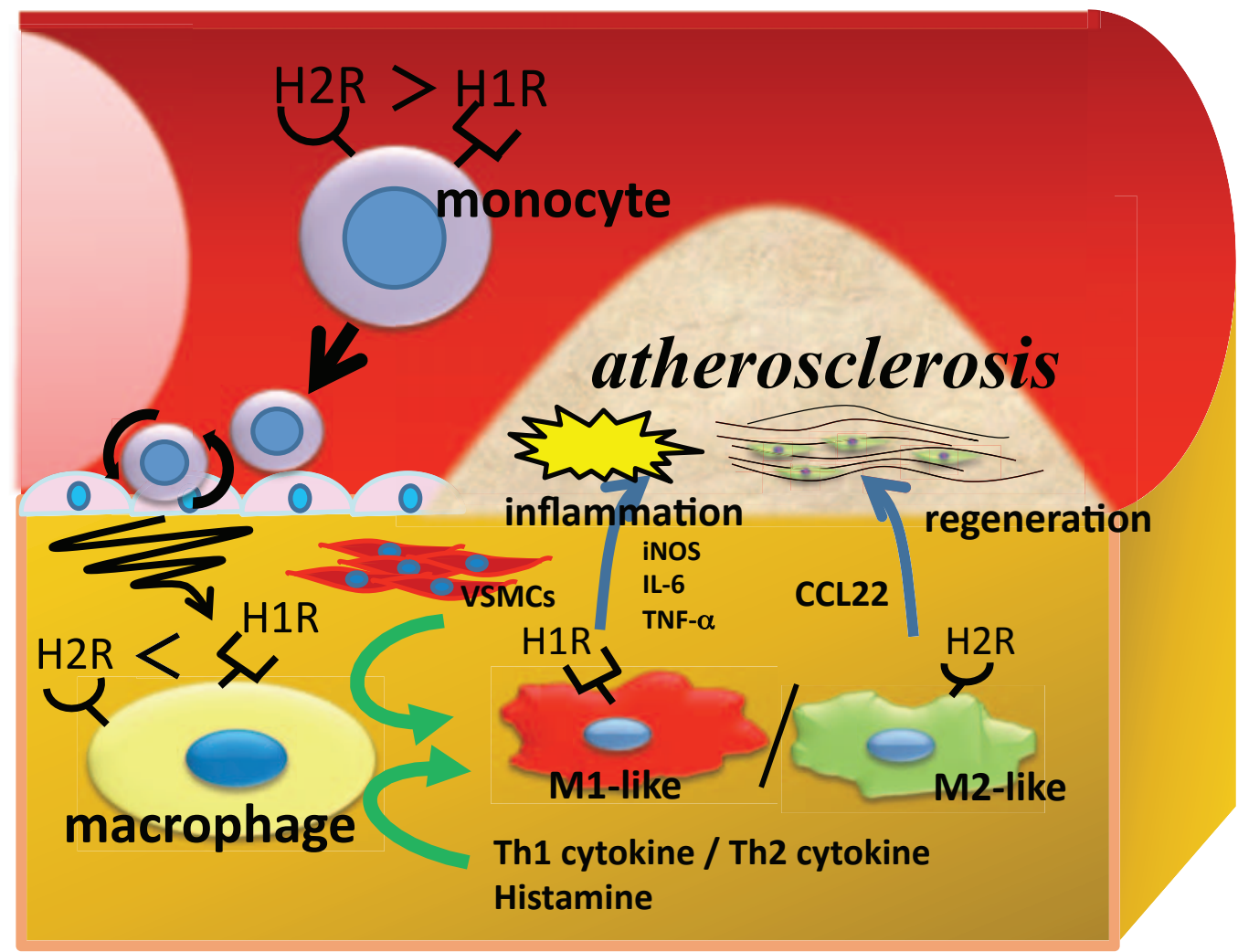

$\mathrm{H} 1 \mathrm{R}=$ histamine receptor $1, \mathrm{H} 2 \mathrm{R}=$ histamine receptor $2, \mathrm{VSMCs}=$ vascular smooth muscle cells, iNOS= inducible nitric oxide synthase, IL- $6=$ interleukin- 6 , TNF- $\alpha=$ tumor necrosis factor- $\alpha$

Fig. 7. Diagram of proposed mechanisms for atherosclerosis

Both M1- and M2-like macrophages are present in atherosclerotic lesions. Their balance is associated with the distribution of VSMC and is regulated by histamine and cytokines that affect atherosclerosis.

$\mathrm{H} 2 \mathrm{R}$ agonists and antagonists on human peripheral blood monocytes, human and mouse monocytes/macrophages ${ }^{19,20)}$, and to macrophage phenotypes (Supplemental Fig. 5). The relationship between the expression of histamine receptors and macrophage subtypes revealed that the $\mathrm{H} 1$ receptor was dominant in M1- like macrophages, whereas in M2-like macrophages a significant difference in expression of $\mathrm{H} 1$ and $\mathrm{H} 2$ receptors was not noted.

Our group has also been studying the causal relationship between histamine and atherosclerosis. In in vitro experiments of atherosclerosis and in the carotid artery-ligated model-mice, the $\mathrm{H} 1$ receptor predominantly induced the development of atherosclerosis ${ }^{21,33)}$; however, in apoE- $\mathrm{KO}$ mice, the $\mathrm{H} 2$ receptor played a major role in the development of atherosclerosis ${ }^{32)}$. In addition, it has also been shown that $\mathrm{H} 1$ antagonists, but not $\mathrm{H} 1$ agonists, increased the progression of atherosclerosis $^{34)}$. IL-4 has long been considered as an anti-atherosclerotic substance and, in fact, is also known to promote atherosclerosis ${ }^{35)}$. The presence of CCL22 was considered to be one reason for such paradoxical phenomena in atherosclerosis.

In conclusion, the expression of $\mathrm{H} 1$ and $\mathrm{H} 2$ receptors, and the migration of Th1 and Th2 cells influenced the expression balance in M1- and M2-like macrophages and may be involved in the processes and progression of atherosclerosis (Fig.7). Although the cellular microenvironment and cell-cell interactions have recently been gaining increasing attention in studies on the pathology of cancer ${ }^{36)}$, it may be that a similar pathology exists in atherosclerosis.

\section{Acknowledgments}

The authors would like to thank Hana Nishimura, Rie Soeda, Yumiko Igawa, Fusa Murayama, Sayumi Kimura, and Miyo Kimura for their expert technical assistance. 


\section{Conflicts of Interest}

The authors declare no conflicts of interest associated with the manuscript.

\section{References}

1) Godiska R, Chantry D, Raport CJ, Sozzani S, Allavena P, Leviten D, Mantovani A, Gray PW. Human macrophagederived chemokine (MDC), a novel chemoattractant for monocytes, monocyte-derived dendritic cells, and natural killer cells. J Exp Med. 1997; 185: 1595-1604

2) Keeley EC, Mehrad B, Strieter RM. Chemokines as mediators of neovascularization. Arteriovascular Thromb Vasc Biol. 2008; 28: 1928-1936

3) Libby P, Hansson GK. Involvement of the immune system in human atherogenesis: current knowledge and unanswered questions. Lab Invest. 1991; 64: 5-15

4) Tjurmin, A. V., Ananyeva NM, Smith EP, Gao Y, Hong MK, Leon MB, Haudenschild CC. Studies on the histogenesis of myxomatous tissue of human coronary lesions. Arterioscler Thromb Vasc Biol. 1999; 19: 83-97

5) Cao W, Bobryshev YV, Lord RS, Oakley RE, Lee SH, Lu J. Dendritic cells in the arterial wall express C1q: Potential significance in atherogenesis. Cardiovasc Res. 2003; 60: $175-186$

6) Greaves DR, Häkkinen T, Lucas AD, Liddiard K, Jones E, Quinn CM, Senaratne J, Green FR, Tyson K, Boyle J, Shanahan C, Weissberg PL, Gordon S, Ylä-Hertualla S: Linked chromosome 16q13 chemokines, macrophage-derived chemokine, fractalkine, and thymus- and activation-regulated chemokine, are expressed in human atherosclerotic lesions. Arterioscler Thromb Vasc Biol. 2001; 21: 923-929

7) Hashimoto S, Suzuki T, Dong HY, Yamazaki N, Matsushima K. Serial analysis of gene expression in human monocytes and macrophages. Blood. 1999; 94: 837-844

8) Hashimoto S, Suzuki T, Dong HY, Nagai S, Yamazaki N, Matsushima K. Serial analysis of gene expression in human monocyte-derived dendritic cells. Blood. 1999; 94: 845852

9) Millonig G, Niederegger H, Rabl W, Hochleitner BW, Hoefer D, Romani N, Wick G. Network of vascular-associated dendritic cells in intima of healthy young individuals. Arterioscler Thromb Vasc Biol. 2001; 21: 503-508

10) Porcheray F, Viaud S, Rimaniol AC, Léone C, Samah B, Dereuddre-Bosquet N, Dormont D, Gras G. Macrophage activation switching: an asset for the resolution of inflammation. Clin Exp Immunol. 2005; 142: 481-489

11) De Paoli F, Staels B, Chinetti-Gbaguidi G. Macrophage phenotypes and their modulation in atherosclerosis. Circ J. 2014; 78: 1775-1781

12) Wynn TA, Vannella KM. Macrophages in tissue repair, regeneration, and fibrosis. Immunity. 2016; 44: 450-462

13) Mantovani A, Garlanda C, Locati M. Macrophage diversity and polarization in atherosclerosis: a question of balance. Arterioscler Thromb Vasc Biol. 2009; 29: 1419-1423

14) Gordon S, Martinez FO. Alternative activation of macrophages: mechanism and functions. Immunity. 2010; 32: 593-604

15) Bouhlel MA, Derudas B, Rigamonti E, Dièvart R, Brozek
J, Haulon S, Zawadzki C, Jude B, Torpier G, Marx N, Staels B, Chinetti-Gbaguidi G. PPARgamma activation primes human monocytes into alternative M2 macrophages with anti-inflammatory properties. Cell Metab. 2007; 6: $137-143$

16) Komohara $Y$, Fujiwara $Y$, Ohnishi K, Shiraishi D, Takeya M. Contribution of Macrophage Polarization to Metabolic Diseases. J Atheroscler Thromb. 2016; 23: 10-17

17) Mantovani A, Sica A, Sozzani S, Allavena P, Vecchi A, Locati M. The chemokine system in diverse forms of macrophage activation and polarization. Trends Immunol. 2004; 25: 677-686

18) Sasaguri Y, Tanimoto A. Role of macrophage-derived histamine in atherosclerosis-- chronic participation in the inflammatory response --. J Atheroscler Thromb. 2004; 11: $122-130$

19) Kimura S, Tanimoto A, Wang KY, Shimajiri S, Guo X, Tasaki T, Yamada S, Sasaguri Y. Expression of macrophagederived chemokine (CCL22) in atherosclerosis and regulation by histamine via the $\mathrm{H} 2$ receptor. Pathol Int. 2012; 62: 675-683

20) Kimura $S$, Wang KY, Yamada $S$, Guo $X$, Nabeshima A, Noguchi H, Watanabe T, Harada M, Sasaguri Y. CCL22/ Macrophage-derived chemokine expression in apolipoprotein E-deficient mice and effects of histamine in the setting of atherosclerosis. J Atheroscler Thromb. 2015; 22: 599-609

21) Yamada $S$, Wang KY, Tanimoto A, Guo X, Nabeshima A, Watanabe T, Sasaguri Y. Histamine receptors expressed in circulating progenitor cells have reciprocal actions in ligation-induced arteriosclerosis. Pathol Int. 2013: 435-447

22) Wang KY, Arima N, Higuchi S, Shimajiri S, Tanimoto A, Murata Y, Hamada T, Sasaguri Y. Switch of histamine receptor expression from $\mathrm{H} 2$ to $\mathrm{H} 1$ during differentiation of monocytes into macrophages. FEBS Lett. 2000; 473: 345-348

23) Ross R. The pathogenesis of atherosclerosis: a perspective for the 1990s. Nature. 1993; 362: 801-809

24) Saiura A, Sata M, Hirata Y, Nagai R, Makuuchi M. Circulating smooth muscle progenitor cells contribute to atherosclerosis. Nat Med. 2001; 7: 382-383

25) Leon ML, Zuckerman SH. Gamma interferon: a central mediator in atherosclerosis. Inflamm Res. 2005; 54: 395 411

26) Doran AC, Meller N, McNamara CA. Role of smooth muscle cells in the initiation and early progression of atherosclerosis. Arterioscler Thromb Vasc Biol. 2008; 28: 812819

27) Filonzi EL, Zoellner H, Stanton H, Hamilton JA. Cytokine regulation of granulocyte-macrophage colony stimulating factor and macrophage-colony stimulating factor production in human arterial smooth muscle cells. Atherosclerosis. 1993; 99: 241-252

28) Seshiah PN, Kereiakes DJ, Vasudevan SS, Lopes N, Su BY, Flavahan NA, Goldschmidt-Clermont PJ. Activated monocytes induce smooth muscle cell death: role of macrophage colony-stimulating factor and cell contact. Circulation. 2002; 105: 174-180

29) Stoneman VE, Bennett MR. Role of apoptosis in atherosclerosis and its therapeutic implications. Clin Sci (Lond). 2004; 107: 343-354 
30) Sasaguri Y, Wang KY, Tanimoto A, Tsutsui M, Ueno H, Murata Y, Kohno Y, Yamada S, Ohtsu H. Role of histamine produced by bone marrow-derived vascular cells in pathogenesis of atherosclerosis. Circ Res. 2005; 96: 974981

31) Yamada S, Wang KY, Tanimoto A, Sasaguri Y. Novel function of histamine signaling in hyperlipidemia-induced atherosclerosis: Histamine $\mathrm{H} 1$ receptors protect and $\mathrm{H} 2$ receptors accelerate atherosclerosis. Pathol Int. 2015; 65: 67-80

32) Cronshaw DG, Kouroumalis A, Parry R, Webb A, Brown Z, Ward SG. Evidence that phospholipase-C-dependent, calcium-independent mechanisms are required for directional migration of T-lymphocytes in response to the CCR4 ligands CCL17 and CCL22. J Leukoc Biol. 2006; 79: 1369-1380

33) Kimura S, Wang KY, Tanimoto A, Murata Y, Nakashima
Y, Sasaguri Y. Acute inflammatory reactions caused by histamine via monocytes/macrophages chronically participate in the initiation and progression of atherosclerosis. Pathol Int. 2004; 54: 465-474

34) Raveendran VV, Smith DD, Tan X, Sweeney ME, Reed GA, Flynn CA, Tawfik OW, Milne G, Dileepan KN. Chronic ingestion of $\mathrm{H} 1$-antihistamines increase progression of atherosclerosis in apolipoprotein E-/- mice. PLoS One. 2014; 9: e102165

35) Davenport P, Tipping PG. The role of interleukin- 4 and interleukin-12 in the progression of atherosclerosis in apolipoprotein E-deficient mice. Am J Pathol. 2003; 163: $1117-1125$

36) Komohara Y, Takeya M. CAFs and TAMs: maestros of the tumour microenvironment. J Pathol. 2017; 241: 313-315 
A

B
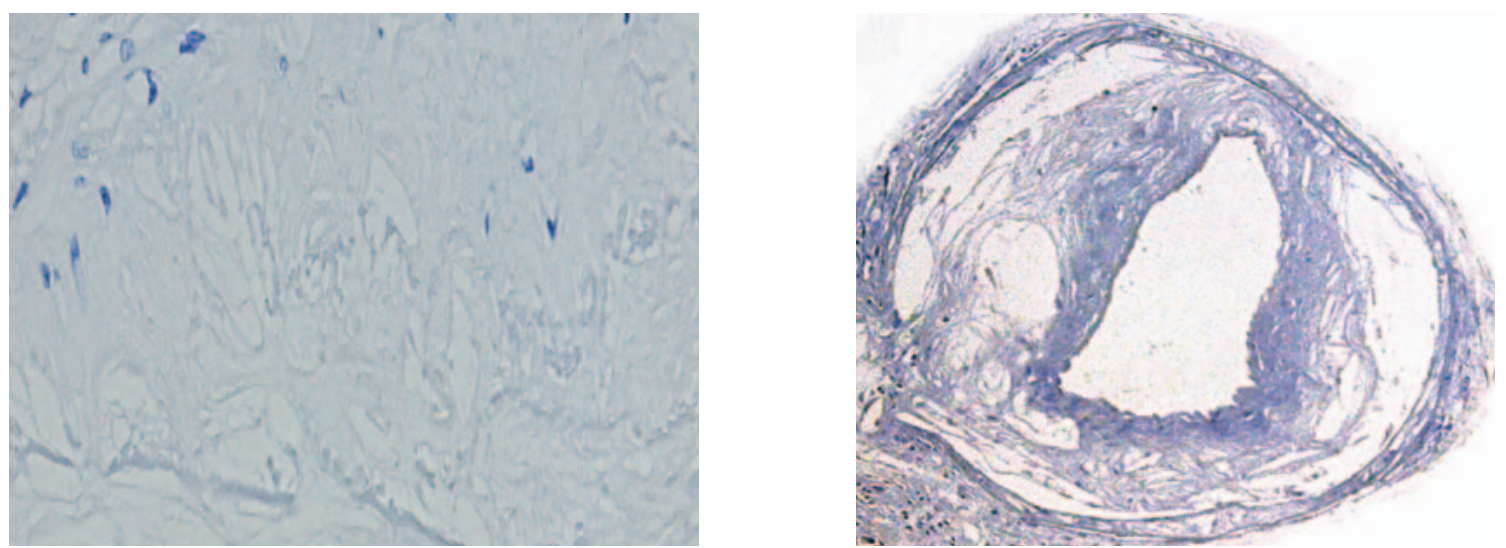

Supplemental Fig. 1. Negative control staining of CCL22 in lipid clefts

Fig. A shows negative control staining of CCL22 in Fig. 1C- $\gamma$, and B is a negative control for the CCL22 stain in Fig. 5A.

A

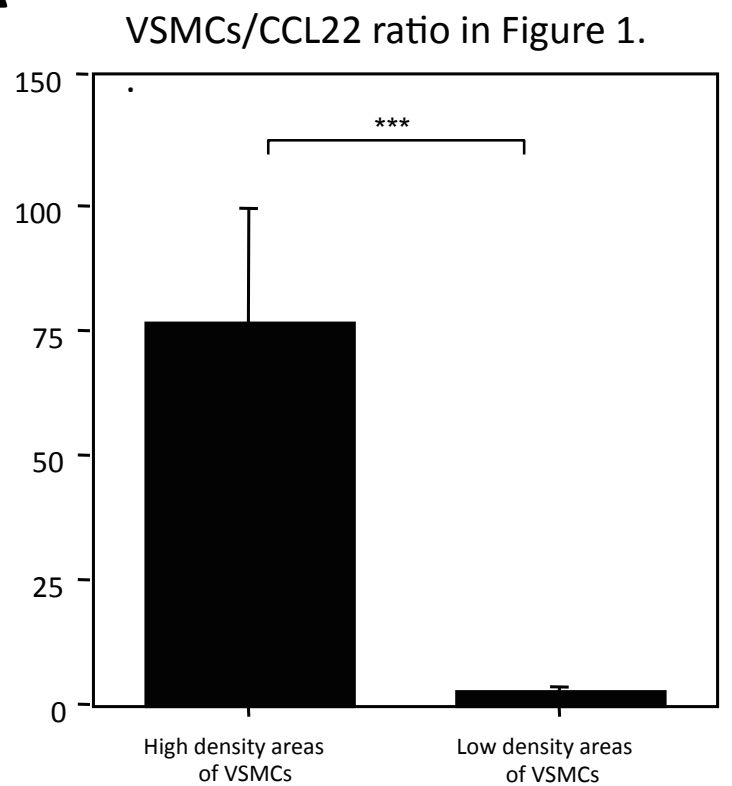

B

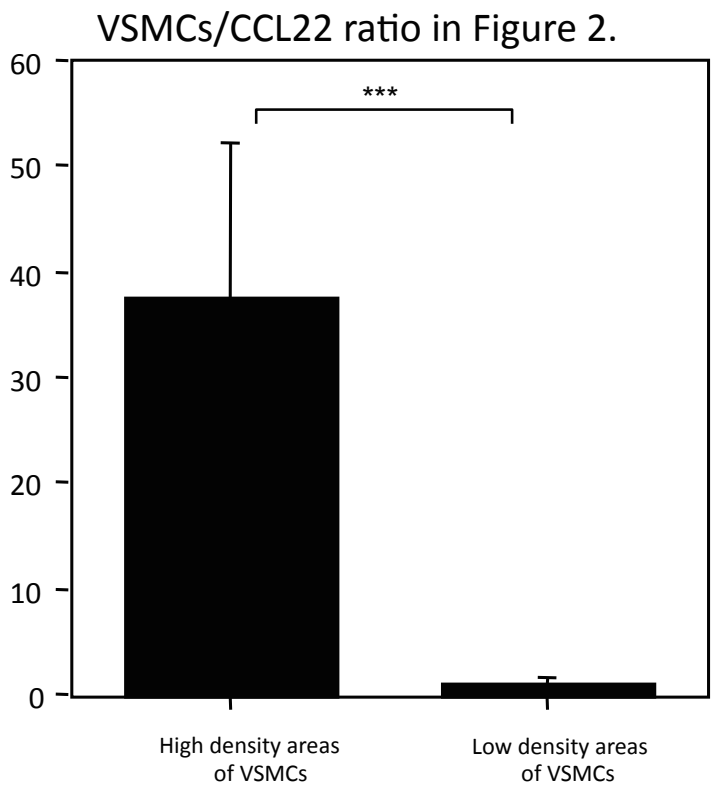

Supplemental Fig. 2. Expression ratios of VSMCs to CCL22

The expression levels of VSMCs and CCL22 were quantified as positive areas by Photoshop CS (Adobe Systems Incorporated, San Jose, CA). A. and B. show the positive area ratios of VSMCs/CCL22 of high and low VSMC density areas in a human common carotid artery (Fig. 1) and human coronary artery with a bare metal stent (Fig. 2). The measurements were performed independently by three pathologists. A significant negative correlation between the expression levels of VSMCs and CCL22 was found.

Values represent the mean $\pm S D$ of triplicate measurements from three independent experiments $(* * * P<0.001)$. 

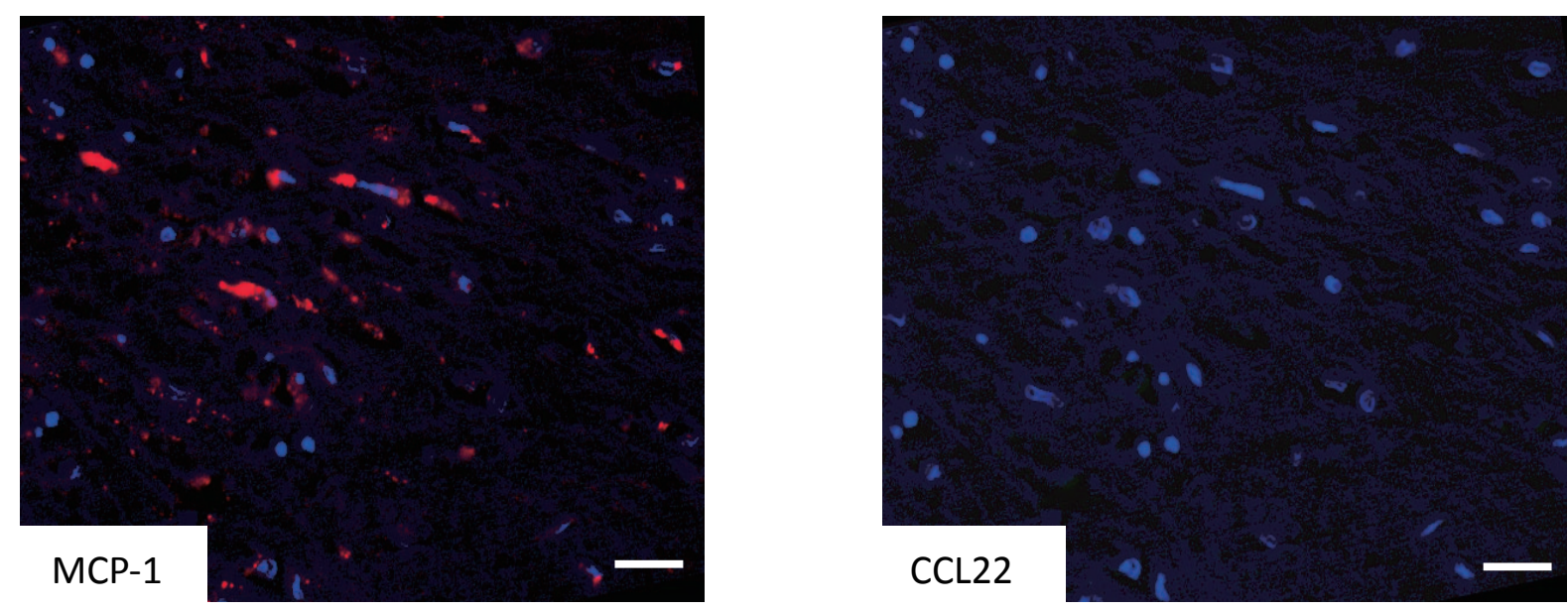

Supplemental Fig. 3. Immunofluorescence staining of MCP-1 and CCL22 in an area with a high degree of VSMC density.

Fig. depict the same area as Fig. 1B- $\beta$. Immunofluorescence staining showed monocyte chemoattractant protein (MCP)-1 (clone 2.2-4H5-01A11, $10 \mu \mathrm{g} / \mathrm{ml}$ PeproTech Inc., Rocky Hill, NJ; red) positive cells were negative for CCL22 (green). Bars indicate $50 \mu \mathrm{m}$.

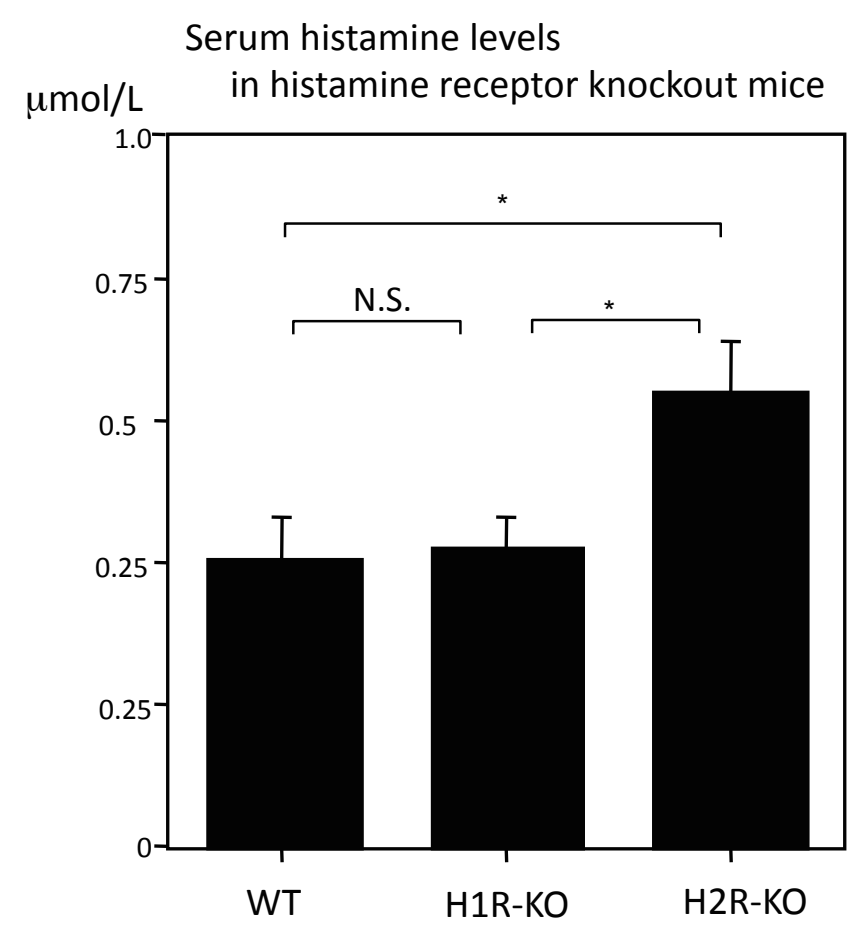

Supplemental Fig.4. The concentration of histamine in sera of histamine receptor knockout mice.

An ELISA (R\&D Systems and Immunotech, Marseille, France) showed that histamine receptor knockout mice (H2R-KO) mice $(n=8)$ had higher serum levels of histamine than WT $(n=8)$, and H1R-KO mice $(n=8)$ that were maintained for 11 weeks on a normal chow diet. Values represent the mean $\pm S D$ of triplicate measurements from three independent experiments $\left({ }^{*} P<0.05\right.$, N.S: not significant). 

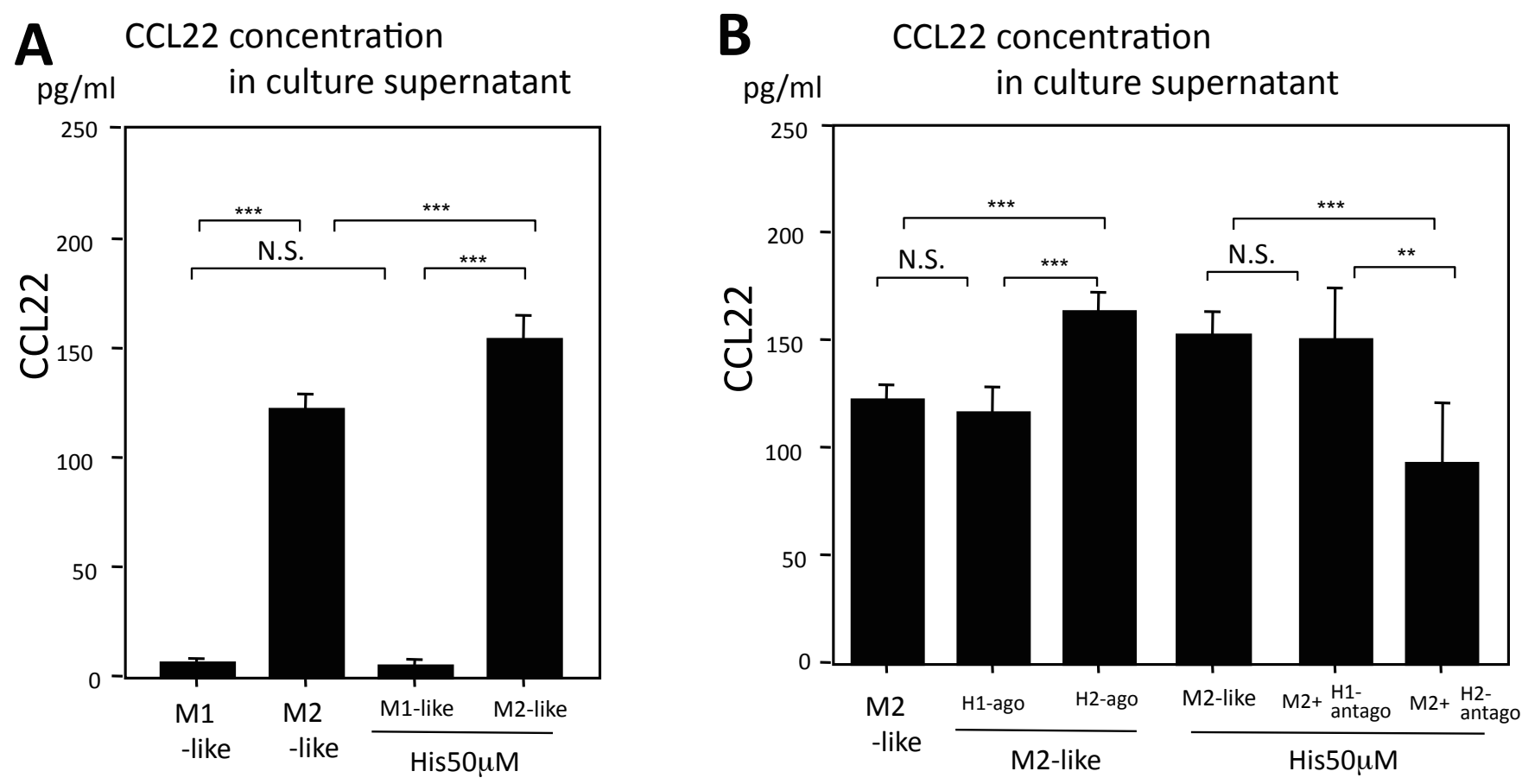

Supplemental Fig. 5. CCL22 expression in response to histamine and effects of histamine agonist and antagonist in J774A.1 cells

A) Culture supernatants of J774A.1 cells $\left(1 \times 10^{6}\right.$ cells/mL) containing CCL22 differentiated into M1-/M2-like cells in 24 h culture with/ without $50 \mu \mathrm{M}$ histamine (Wako) were measured by enzyme-linked immunoassay (ELISA; R\&D Systems, Minneapolis, MN, USA). Histamine increased the concentration of CCL22 in the culture supernatant of M2-like macrophages. In contrast, M1-like macrophages were hardly affected by histamine, and did not significantly express CCL22 protein compared with M2-like macrophages.

B) Expression of CCL22 in J774A.1 cells incubated for $24 \mathrm{~h}$ with $50 \mu \mathrm{M}$ histamine, $50 \mu \mathrm{M} \mathrm{H} 1$ or $50 \mu \mathrm{M}$ H2 receptor agonist (2-pyridylethylamine dihydrochloride and dimaprit dihydrochloride, respectively from Wako), or $50 \mu \mathrm{M}$ histamine added with $10 \mu \mathrm{M}$ pyrilamine (H1 receptor blocker from Sigma) or $50 \mu \mathrm{M}$ histamine added with $10 \mu \mathrm{M}$ cimetidine (H2 receptor blocker from Sigma).

CCL22 levels increased significantly when the histamine H2 agonist was added to the culture, but were not influenced by the histamine H1 agonist. The increase of CCL22 from M2-macrophages by $50 \mu \mathrm{M}$ histamine stimulation was significantly reduced by the addition of pyrilamine, but not cimetidine.

$\mathrm{H} 1$-ago $=2$-pyridylethylamine dihydrochloride, $\mathrm{H} 2$-ago $=$ dimaprit dihydrochloride, $\mathrm{H} 1$-antago $=$ pyrilamine, $\mathrm{H} 2$-antago $=$ cimetidine The values are the mean $\pm \mathrm{SD}$ of triplicate measurements from 3 independent experiments $\left(* * P<0.01\right.$, ${ }^{* * *} P<0.001$, N.S: not significant). 